\title{
Profit Maximization Model with Fare Structures and Subsidy Constraints for Urban Rail Transit
}

\author{
Qing Wang $\mathbb{D}^{1,2}$ Paul Schonfeld $\mathbb{D},^{3}$ and Lianbo Deng $\mathbb{D}^{1}$ \\ ${ }^{1}$ School of Traffic and Transportation Engineering, Rail Data Research and Application Key Laboratory of Hunan Province, \\ Central South University, Changsha 410075, China \\ ${ }^{2}$ Department of Civil and Environmental Engineering, University of Washington, Seattle, WA 98105, USA \\ ${ }^{3}$ Department of Civil and Environmental Engineering, University of Maryland, College Park 1173 Glenn Martin Hall, \\ College Park, MD 20742, USA
}

Correspondence should be addressed to Lianbo Deng; lbdeng@csu.edu.cn

Received 15 November 2020; Revised 29 December 2020; Accepted 13 January 2021; Published 25 January 2021

Academic Editor: Erfan Hassannayebi

Copyright (c) 2021 Qing Wang et al. This is an open access article distributed under the Creative Commons Attribution License, which permits unrestricted use, distribution, and reproduction in any medium, provided the original work is properly cited.

This paper analyzes government subsidies based on the service design (i.e., headway) and fare structures of an urban rail transit system while considering necessary financial support from the government. To capture the interactions among the operator performance, government subsidies, and passengers in an urban rail transit system, a profit maximization model with nonnegative profit constraint is formulated to determine the optimal fare and headway solutions. Then, the social welfare that results from the operator profit maximization model is analyzed. Finally, a numerical example from Changsha, China, is employed to verify the feasibility of the proposed model. The major results consist of optimized solutions for decision variables, i.e., the fares and train headways, as well as subsidies to the operator. The fare elasticity factor under two fare structures significantly affects fares and demand. As the fare elasticity factor increases, the social welfare gradually decreases and a deficit occurs at low fares and demand, while subsidies rise from 0 to $¥ 24658.00$ and $¥ 38089.16$ under the flat fare and distance-based fare structures.

\section{Introduction}

In recent decades, large-scale investment by local authorities in China has greatly promoted the pace of urban rail transit (URT) construction and operation. According to the "Annual Statistics and Analysis Report of URT 2019", up to the end of 2019, there were 208 URT lines in (mainland) China, distributed in 40 cities, including Shanghai, Beijing, Guangzhou, and Nanjing, with a total length of $5180.6 \mathrm{~km}$ in operation, and the ridership has exceeded 237.1 billion passengers per year. In general, operators in most cities are overdependent on the government's subsidies (data source: China Association of Metros, 2019 [1]).

A comprehensive review of the transportation issues was conducted by Farahani et al. [2], which discussed and compared the models and solution methods of transportation network design problem. Although many studies have investigated the optimization of public transportation, the literature on methods for optimizing URT system operation with subsidy constraints while considering different fare structures is still relatively scarce. For instance, $\mathrm{Li}$ and Love [3] conducted a retrospective analysis of a rail line that was procured using a public-private partnership in conjunction with land value capture. They showed that the economic viability of that URT system could be ensured by considering the land value capture. Canca et al. [4] developed a mathematical programing model that maximized net profit by simultaneously determining the infrastructure network and line planning problem. The effect of a surcharge-reward scheme relieving crowding and queuing congestion in a URT system was investigated in Tang et al. [5], who formulated a bilevel model to design and optimize the surcharge-reward scheme. Since fares are closely related to operator profit and subsidies, the implementation of fare differentiation is one of the practical policies adopted in public transport management [6]. Further studies on the 
relations between fares and operator performance as well as passenger travel behavior have been conducted. For example, a model was developed to optimize the transit fare structure with demand elasticity, but with a fixed service frequency [7]. Then, Chien and Spasovic [8] proposed a model that optimized fares by considering demand without excessively simplifying spatial characteristics and demand patterns. The work of Chien and Spasovic [8] was extended by Sharaby and Shiftan [9], who studied the impacts of fares on demand and travel behavior. The optimization of fares has often been related to the service frequency (or its inverse, the headway, in this study), which has been investigated by many researchers. Chien and Tsai [10] constructed an optimization model for maximizing profits and considered the impact of varying demand on headway and fare. Jin et al. [11] proposed a social welfare maximization model for optimizing fare levels by considering the demand and service quality of public transport. Wang and Deng [12] developed a model for optimizing distance-based fare structure (DBF) and headway by considering the maximum operator profit and minimum per capita subsidy for passengers. Besides, passengers consider many factors in their travel choices, including service levels, generalized travel time, and fares [13]. These factors can be subsumed into the passenger travel behavior of public transportation systems.

Different fare structures are mainly used as one of the indicators for evaluating passenger travel behavior, operator performance, and other aspects. For flat fare structure (FF) optimization, Wang et al. [14] investigated public transit service (i.e., flat fare and frequency) operation strategies in a bimodal network. Jin et al. [11] focused on a flat fare structure and found that low fares are preferable from the viewpoint of maximizing social welfare. For DBF optimization, Tsai et al. [15] proposed a profit maximization model for maximizing DBF and service headway. Through sensitivity analyses, the results indicate that the optimized fare and headway decrease as the demand increases, which results in a profit increase. In addition, some studies also proposed models that optimized other fare structures, such as a zonal fare [13], a sectional fare [16], and an OriginDestination (OD) fare [17]. Besides, several papers have discussed the feasibility and importance of FF and DBF [18]. The present study only considers FF and DBF since these two are the most widely used fare structures in public transportation.

Another stream of the literature related to our work focuses on operator performance and passenger travel behavior. A series of studies have been conducted to analyze the operators' performance. A model that optimizes operator performance such as frequency and vehicle fleet sizes with financial policies was formulated by Jara-Díaz and Gschwender [19], which investigated the effect that overall economic policies may have on the operation of public service. The efficiency of and the substitutability between different management policies have been analyzed in [20]. The model features operator performance between cars and transit. Several studies have analyzed the passengers' travel characteristics. Gkritza et al. [21] pointed out that riders are sensitive to changes in absolute fare levels as well as relative price. Considering the effect of fares on passenger travel behavior, Nassi and Costa [22] evaluated a region's optimal fare system by using the analytic hierarchy process (AHP). Table 1 highlights the novelties of the model proposed in this paper through comparison with previous studies.

As reviewed above, previous studies have optimized fare structures and subsidies separately, but no published study has compared the impact of subsidies for different fare structures by considering social welfare. More related to our study, several scholars have investigated operation performance with subsidy constraints. To explore different financial constraints, Zhou et al. [23] proposed a maximum social welfare model for optimizing bus transit systems. Through numerical study, the results showed that the effects of subsidies on social welfare differed for fixed and flexibleroute bus systems. Wang and Deng [12] studied the impact of per capita subsidy on passengers and proposed an efficiency-oriented model for maximizing the efficiency of per capita subsidy. A break-even subsidy model for optimizing fares and headways has been developed by Wang et al. [24]. This study identified the effect of two fare structures and headway on operational subsidies.

We recognize that the subsidy to operators may be related to operator performance and fare structures. Our work is extended from Zhou et al. [23] and Wang et al. [24] by considering the impact of fare structures and operator performance on operations. Therefore, we formulate a profit maximization model for operators who charge fares that optimize social welfare and determine the headway optimized in response to the government's financial constraints. The major contributions of this paper are summarized as follows:

(i) This research comprehensively considers subsidy constraints and fare structures of URT system optimization to determine the operator performance and passenger travel behavior. A profit maximization model, with a many-to-many demand pattern, for optimizing fares and headways to maximize the operator profit is developed by considering flat fare (FF) and distance-based fare (DBF) structures as well as a subsidy constraint.

(ii) This paper compares the performance of FF and DBF structures through numerical studies. It is found that FF requires more subsidies and is more attractive for long-distance passengers, while DBF is more profitable and attractive for short-distance passengers.

(iii) We investigate the operator performance under the government's subsidy constraints and different fare structures and compare the effectiveness of the two fare structures at attracting passenger demand and maximizing social welfare. Through the operator profit maximization model with fare structures and subsidy constraints, we obtain the levels of the demand and fares that require no subsidy.

(iv) We obtain the optimal function of fare and headway. Besides, the fare levels significantly affect operator performance, thus affecting subsidies to 
TABLE 1: Related studies.

\begin{tabular}{|c|c|c|c|c|c|}
\hline \multirow{2}{*}{ Citation } & \multirow{2}{*}{ Considering social welfare } & \multicolumn{2}{|c|}{$\begin{array}{c}\text { Fare } \\
\text { structures }\end{array}$} & \multirow{2}{*}{ Considering subsidy } & \multirow{2}{*}{$\begin{array}{c}\text { Demand pattern } \\
\text { Many-to-many elastic demand }\end{array}$} \\
\hline & & FF & DBF & & \\
\hline Chien and Spasovic [8] & $\checkmark$ & $\checkmark$ & - & - & $\checkmark$ \\
\hline Chien and Tsai [10] & - & $\checkmark$ & $\checkmark$ & - & $\checkmark$ \\
\hline Wang and Deng [12] & - & & $\checkmark$ & $\checkmark$ & $\checkmark$ \\
\hline Huang et al. [17] & - & & $\checkmark$ & $\checkmark$ & $\checkmark$ \\
\hline Jara-Díaz and Gschwender [19] & $\checkmark$ & $\checkmark$ & - & $\checkmark$ & - \\
\hline Basso and Silva [20] & - & $\checkmark$ & - & $\checkmark$ & - \\
\hline Zhou et al. [23] & - & $\checkmark$ & - & $\checkmark$ & - \\
\hline Wang et al. [24] & - & $\checkmark$ & $\checkmark$ & $\checkmark$ & $\checkmark$ \\
\hline Sun et al. [25] & $\checkmark$ & $\checkmark$ & - & $\checkmark$ & - \\
\hline Ling et al. [26] & - & $\checkmark$ & - & $\checkmark$ & - \\
\hline This study & $\checkmark$ & $\checkmark$ & $\checkmark$ & $\checkmark$ & $\checkmark$ \\
\hline
\end{tabular}

operators. Comparing the effects of changes in fare elasticity factor on subsidies, we find that the fare elasticity factor affects the DBF fare rate (i.e., the variable component of DBF fare) more than the FF fare and affects the revenue more than the operating cost under FF and DBF.

The paper is organized as follows. In the next section, preliminaries are described, including the URT network characteristics and important functions related to optimization models. Section 3 presents the operator profit models under FF and DBF and provides the solution discussion for two models. The performance and application of our proposed models are evaluated through numerical experiments in Section 4. Finally, conclusions with major findings as well as prospective research directions are provided in Section 5.

\section{Preliminaries}

In this paper, a URT line is represented by $(S, E)$, which contains the station set and section set. Let $S=\{1,2, \ldots, N\}$ be the set of nodes for stations and let $E=\left\{e_{i j} \mid i, j \in S\right\}$ be the set of sections for the line. For each section $e_{i j} \in E$, the distance between stations $i$ and $j(i, j \in S)$ is $d_{i j}$. Let $D_{S}, S=$ $1,2, \ldots, N$ represent the total length of the line between the OD stations. The following assumptions are made before formulating the models.

(i) Assumption 1. The URT trains are assumed to have the same number of railcars and the same fixed dwell times at each station.

(ii) Assumption 2. The study period is assumed to be one hour, i.e., demand is an average hourly passenger flow of the day. We neglect here the differences between peak and off-peak hours in order to focus on subsidies, fare structures, and operator profit maximization model.

(iii) Assumption 3. All revenue of operators is obtained from fares, and no other revenue sources are considered (e.g., advertisement revenue). This means that the subsidies found here are only related to operations. (iv) Assumption 4. The average waiting time of passengers at all stations along a URT line is the same constant fraction of the headway, i.e., usually half of the headway if passengers and trains arrive uniformly over time.

2.1. Fare Structures. Since FF and DBF are considered here the fare per passenger trip can be written as follows:

$$
P= \begin{cases}\widetilde{P}, & (\text { for } \mathrm{FF}), \\ \widehat{P}=p_{0}+\widehat{p} d_{i j}, & (\text { for } \mathrm{DBF}),\end{cases}
$$

where the fare, $\widehat{P}$, for DBF includes a fixed component $p_{0}$ and a variable component, $\widehat{p}$.

2.2. Elastic Demand Function. Let $Q_{i j}$ be the URT passenger volume from stations $i$ to $j$ and $q_{i j}$ be the potential demand during the study period. Referring to Wang and Deng [12] and Wang et al. [24], we can obtain the passenger elastic demand function:

$$
Q_{i j}=q_{i j}\left(1-e_{w} w_{t}-e_{r} r_{t}-e_{p} P\right),
$$

where $w_{t}, r_{t}$ are the waiting time per passenger and train riding time, respectively, and $e_{w}, e_{r}, e_{p}$ are parameters for waiting time, riding time, and fare, respectively.

The total riding time of passengers between stations $i$ and $j$ is the sum of the train running time, $\left(d_{i j} / v\right)$, and train dwell time, $|j-i-1| \cdot t_{0}$, where $t_{0}$ is the average train dwell time at each station. The passenger riding time, $r_{t}$, can be expressed as

$$
r_{t}=\frac{d_{i j}}{v}+|j-i-1| \cdot t_{0} .
$$

According to assumption 4, the average passenger waiting time is $w_{t}=\sigma \cdot H$, where $\sigma=0.5$ is the waiting time parameter. Thus, (2) can be rewritten as

$$
Q_{i j}=q_{i j}\left(1-e_{w} \sigma H-e_{r} r_{t}-e_{p} P\right) .
$$

To ensure the nonnegativity of the demand, the elastic demand function should satisfy the following condition: 


$$
0 \leq 1-e_{w} \sigma H-e_{r} r_{t}-e_{p} P \leq 1 .
$$

2.3. Operating Costs Function. Following Wang et al. [24], the total operating cost consists of three components: train operating cost $\left(C_{T}\right)$, rail line maintenance and operation cost $\left(C_{L}\right)$, and station service and operation cost $\left(C_{S}\right)$; i.e.,

$$
C=C_{T}+C_{L}+C_{S} .
$$

The train operating cost includes the variable cost, $N c_{O}$ (i.e., the cost of trains operating on the line), and the fixed cost, $\beta \varepsilon N c_{O}$ (i.e., the cost of reserve trains waiting to be operated), which can be expressed as

$$
C_{T}=N c_{O}+\beta \varepsilon N c_{O} .
$$

The number and cost of reserve trains are, respectively, $\varepsilon$ times and $\beta$ times those of the operating trains. In (7), the number of operating trains, $N=\left(T_{R} / H\right)$, equals the train round trip time, $T_{R}$, divided by the headway, $H$. The train round trip time is $T_{R}=2\left(\left(D_{s} / v\right)+L_{S} t_{0}\right)+t_{z}$, comprising the nonstop line-haul travel time $\left(D_{s} / v\right)$, dwell time, $L_{S} t_{0}$, and the train reversing time $t_{z}$.

The second term is the sum of the variable cost, $\left(\gamma_{1} / H\right)$ (the cost for line use related to the operating frequency $1 / H$ ) and the fixed cost $\gamma_{0} D_{s}$ (i.e., the cost of the rail line maintenance related to the total length of the line), which can be expressed as

$$
C_{L}=\gamma_{0} D_{s}+\frac{\gamma_{1}}{H}
$$

The last term comprises the fixed cost for a station operating and variable cost (i.e., the number of passengers served per hour). The service costs grow linearly with the passenger volume at each station, which can be expressed as

$$
C_{S}=\Lambda_{0} L_{S}+\Lambda_{1} \sum_{i, j \in S} q_{i j}\left(1-e_{w} \sigma H-e_{r} r_{t}-e_{p} P\right) .
$$

Then, the operating cost function $(C)$ under FF and DBF can be reformulated as follows:

$$
C= \begin{cases}\widetilde{C}=(1+\beta \varepsilon) \frac{T_{R}}{\widetilde{H}} \cdot c_{O}+\left(\gamma_{0} D_{s}+\frac{\gamma_{1}}{\widetilde{H}}\right)+\Lambda_{0} L_{S}+\Lambda_{1} \sum_{i, j \in S} Q_{i j}, & (\text { for FF }), \\ \widehat{C}=(1+\beta \varepsilon) \frac{T_{R}}{\widehat{H}} \cdot c_{O}+\left(\gamma_{0} D_{s}+\frac{\gamma_{1}}{\widehat{H}}\right)+\Lambda_{0} L_{S}+\Lambda_{1} \sum_{i, j \in S} Q_{i j}, & \text { (for DBF). }\end{cases}
$$

2.4. Revenue Function. According to assumption 3, the revenue of the URT system is a sum of the fares paid by all passengers. The revenue function $(R)$ under FF and DBF can be expressed as

$$
R= \begin{cases}\widetilde{R}=\widetilde{P} \cdot \sum_{i, j \in S} q_{i j}\left(1-e_{w} \sigma \widetilde{H}-e_{r} r_{t}-e_{p} \widetilde{P}\right), & (\text { for } \mathrm{FF}), \\ \widehat{R}=\sum_{i, j \in S} \widehat{P} \cdot q_{i j}\left(1-e_{w} \sigma \widehat{H}-e_{r} r_{t}-e_{p} \widehat{P}\right), & (\text { for } \mathrm{DBF}) .\end{cases}
$$

\section{Model Formulation}

3.1. Operator Profit Maximization Model. In this section, operator profit maximization model is analyzed with a subsidy constraint under two fare structures (i.e., FF and DBF). The decision variables are headway $H$ and fare $P$. In view of $(1)-(11)$, the operator profit $(\tilde{\pi}(\tilde{H}, \widetilde{P})$ or $\widehat{\pi}(\widehat{H}, \widehat{P}))$ maximization problem can be formulated as follows. For FF,

subject to

$$
\begin{aligned}
\tilde{\pi}(\tilde{H}, \widetilde{P})= & \widetilde{P} \cdot \sum_{i, j \in S} q_{i j}\left(1-e_{w} \sigma \widetilde{H}-e_{r} r_{t}-e_{p} \widetilde{P}\right) \\
& -\left((1+\beta \varepsilon) \frac{T_{R}}{\widetilde{H}} \cdot c_{O}+\left(\gamma_{0} D_{s}+\frac{\gamma_{1}}{\widetilde{H}}\right)+\Lambda_{0} L_{S}+\Lambda_{1} \sum_{i, j \in S} q_{i j}\left(1-e_{w} \sigma \widetilde{H}-e_{r} r_{t}-e_{p} \widetilde{P}\right)\right),
\end{aligned}
$$

$$
\widetilde{R}-\widetilde{C}+\widetilde{S}_{\text {flat }} \geq 0
$$


For DBF,

$$
\begin{aligned}
& \widehat{\pi}(\widehat{H}, \widehat{P})= \sum_{i, j \in S} \widehat{P} \cdot q_{i j}\left(1-e_{w} \sigma \widehat{H}-e_{r} r_{t}-e_{p} \widehat{P}\right) \\
&-\left((1+\beta \varepsilon) \frac{T_{R}}{\widehat{H}} \cdot c_{O}+\left(\gamma_{0} D_{s}+\frac{\gamma_{1}}{\widehat{H}}\right)+\Lambda_{0} L_{S}+\Lambda_{1} \sum_{i, j \in S} q_{i j}\left(1-e_{w} \sigma \widehat{H}-e_{r} r_{t}-e_{p} \widehat{P}\right)\right), \\
& \widetilde{S}_{\text {flat }}=\max \{\widetilde{C}-\widetilde{R}, 0\} .
\end{aligned}
$$

subject to

$$
\widehat{R}-\widehat{C}+\widehat{S}_{\text {distance }} \geq 0 \text {. }
$$

Constraint (i.e., $R-C+S \geq 0$ ) guarantees the nonnegativity of the operator profit. Thus, the profit should be nonnegative after the government's subsidies.

3.2. Solution Discussion. It is easy to verify that the operator profit function is concave with respect to decision variables, i.e., fare and headway (more details are shown in Appendix A.). Therefore, we consider the first-order conditions of (12) or (14); i.e., set to zero the partial derivative of the objective function $\widetilde{\pi}(\widetilde{H}, \widetilde{P})$ (or $\widehat{\pi}(\widehat{H}, \widehat{P}))$ with respect to $\widetilde{H}$ (or $\widehat{H}$ ) and $\widetilde{P}$ (or $\widehat{P})$, and obtain the functions for the optimal fare and headway as follows.

For FF,

$$
\left\{\begin{array}{l}
\widetilde{P}^{*}=\frac{\sum_{i, j \in S} q_{i j}\left(1-e_{w} \sigma \widetilde{H}-e_{r} r_{t}+\Lambda_{1} e_{p}\right)}{2 e_{p} \sum_{i, j \in S} q_{i j}}, \\
\widetilde{H}^{*}=\sqrt{\frac{(1+\beta \varepsilon) T_{R} \cdot c_{O}+\gamma_{1}}{e_{w} \sigma\left(\widetilde{P}-\Lambda_{1}\right) \sum_{i, j \in S} q_{i j}}}
\end{array}\right.
$$

For DBF,

$$
\left\{\begin{array}{l}
\widehat{P}^{*}=\frac{\sum_{i, j \in S} d_{i j} q_{i j}\left(1-e_{w} \sigma \widehat{H}-e_{r} r_{t}+e_{p} \Lambda_{1}\right)}{2 e_{p} \sum_{i, j \in S} q_{i j} \mathrm{~d}_{i j}}, \\
\widehat{H}^{*}=\sqrt{\frac{(1+\beta \varepsilon) T_{R} \cdot c_{O}+\gamma_{1}}{e_{w} \sigma \sum_{i, j \in S} q_{i j}\left(\left(p_{0}+\widehat{p} d_{i j}\right)-\Lambda_{1}\right)}} .
\end{array}\right.
$$

In the subsidization scheme, a government provides subsidies to compensate for operating deficit if and when the operator faces a negative profit [27]. The subsidy should satisfy the following.

For FF,
For DBF,

$$
\widehat{S}_{\text {distance }}=\max \{\widehat{C}-\widehat{R}, 0\} \text {. }
$$

Substituting (16) and (17) into (18) and (19), we can obtain the subsidy to an operator under for FF and DBF as follows.

For FF,

$$
\begin{aligned}
\widetilde{S}_{\text {flat }}^{*}= & \max \left\{(1+\beta \varepsilon) \frac{c_{O} T_{R}}{\widetilde{H}^{*}}+\left(\gamma_{0} D_{s}+\frac{\gamma_{1}}{\widetilde{H}^{*}}\right)+\Lambda_{0} L_{S}\right. \\
& \left.+\left(\Lambda_{1}-\widetilde{P}^{*}\right) \sum_{i, j \in S} q_{i j}\left(1-e_{w} \sigma \widetilde{H}^{*}-e_{r} r_{t}-e_{p} \widetilde{P}^{*}\right), 0\right\} .
\end{aligned}
$$

For DBF,

$$
\begin{aligned}
\widehat{S}_{\text {distance }}^{*}= & \max \left\{(1+\beta \varepsilon) \frac{c_{O} T_{R}}{\widehat{H}^{*}}+\left(\gamma_{0} D_{s}+\frac{\gamma_{1}}{\widehat{H}^{*}}\right)+\Lambda_{0} L_{S}\right. \\
& +\sum_{i, j \in S}\left(\Lambda_{1}-\widehat{P}^{*}\right) q_{i j}\left(1-e_{w} \sigma \widehat{H}^{*}-e_{r} r_{t}\right. \\
& \left.\left.-e_{p}\left(p_{0}+\widehat{p} d_{i j}\right)\right), 0\right\} .
\end{aligned}
$$

In general, the user surplus is computed as the integral of the fare function (that is, the inverse of the demand function) concerning the total passenger volume. Following Sun et al. [25], let $B(P)$ be the inverse demand function of the elastic demand function [28].

$$
B(P)=Q_{i j}^{-1}=\frac{1-e_{w} w_{t}-e_{r} r_{t}-\left(Q / \sum_{i, j \in S} q_{i j}\right)}{e_{p}} .
$$

Then, the user surplus $U$ can be expressed as follows: 


$$
U= \begin{cases}\widetilde{U}=\int_{0}^{Q_{i j}}(B(\widetilde{P})-\widetilde{P}) \mathrm{d} q=\frac{1}{2 e_{p}} \sum_{i, j \in S} q_{i j}\left(1-e_{w} \sigma \widetilde{H}-e_{r} r_{t}-e_{p} \widetilde{P}\right)^{2}, & (\text { for FF), } \\ \widehat{U}=\int_{0}^{Q_{i j}}(B(\widehat{P})-\widehat{P}) \mathrm{d} q=\frac{1}{2 e_{p}} \sum_{i, j \in S} q_{i j}\left(1-e_{w} \sigma \widehat{H}-e_{r} r_{t}-e_{p} \widehat{P}\right)^{2}, & \text { (for DBF). }\end{cases}
$$

We now compute the social welfare resulting from the fare and headway obtained by the profit maximization model with subsidy constraints. Combining profit and user surplus, social welfare $(Y(\widetilde{P}, \widetilde{H})$ or $Y(\widehat{P}, \widehat{H}))$ can be written as follows.

For FF,

$$
\begin{aligned}
Y(\widetilde{P}, \widetilde{H})= & \left(\widetilde{P}-\Lambda_{1}\right) \cdot \sum_{i, j \in S} q_{i j}\left(1-e_{w} \sigma \widetilde{H}-e_{r} r_{t}-e_{p} \widetilde{P}\right) \\
& -(1+\beta \varepsilon) \frac{T_{R}}{\widetilde{H}} \cdot c_{O}-\left(\gamma_{0} D_{S}+\frac{\gamma_{1}}{\widetilde{H}}\right) \\
& -\Lambda_{0} L_{S}+\frac{1}{2 e_{p}} \sum_{i, j \in S} q_{i j}\left(1-e_{w} \sigma \widetilde{H}-e_{r} r_{t}-e_{p} \widetilde{P}\right)^{2} .
\end{aligned}
$$

For DBF,

$$
\begin{aligned}
Y(\widehat{P}, \widehat{H})= & \sum_{i, j \in S}\left(\widehat{P}-\Lambda_{1}\right) \cdot q_{i j}\left(1-e_{w} \sigma \widehat{H}-e_{r} r_{t}-e_{p} \widehat{P}\right) \\
& -(1+\beta \varepsilon) \frac{T_{R}}{\widetilde{H}} \cdot c_{O}-\left(\gamma_{0} D_{S}+\frac{\gamma_{1}}{\widehat{H}}\right) \\
& -\Lambda_{0} L_{S}+\frac{1}{2 e_{p}} \sum_{i, j \in S} q_{i j}\left(1-e_{w} \sigma \widehat{H}-e_{r} r_{t}-e_{p} \widehat{P}\right)^{2} .
\end{aligned}
$$

\section{Numerical Study}

We illustrate an application of the proposed models for Changsha's Metro Line 2 in China. A numerical study investigates the effects of the key model variables and subsidies for different fare structures. In the following analysis, the baseline values of parameters are set as follows:

The average speed is assumed to be $40 \mathrm{~km} / \mathrm{h}$, while the average train dwell time, train reserving time, and passenger waiting time at each station are set to be $1 / 120 \mathrm{~h}, 0.08 \mathrm{~h}$, and $0.5 \mathrm{~h}$, respectively. The hourly operating cost is $¥ 1950 /$ vehicle-hour, the unit fixed cost of the line is $¥ 3800 / \mathrm{km}$, and the unit fixed cost of each station is $¥ 4200 / \mathrm{km}-\mathrm{hr}$. The demand elasticity parameters for waiting time, riding time, and fare are set at $0.6,0.15$, and 0.1 , respectively. The upper and lower boundary of the train operating headway are set at $1 / 30$ (or 2 minutes) and 1/5 (or 12 minutes), while those of the fare are set at 0 and 12, respectively. The values of other input parameters are shown in Table 2. Note that additional references for these parameters can be found in Wang and Deng [12], Wang et al. [24], and China Railway Fourth
Survey and Design Institute Group Co., Ltd. [29]. The values for the demand elasticity parameters are estimated based on historical data $[12,24]$. The actual data of Changsha's URT line 2 are obtained from a survey conducted during the planning period, as shown in [29].

4.1. Numerical Results. The optimized results for the operator profit (OP) models under FF and DBF are presented in Table 3. The results are slightly different for two fare structures, while the headways and fare levels are extremely sensitive to the objective. For comparison, optimized solutions are provided from the OP models with fare structures and subsidy constraints. Decision variables at which the OP model maximizes profit are $¥ 4.88$ for fare and $8.56 \mathrm{~min}$ for headway under FF. For DBF, the corresponding optimized values are $¥\left(1.97+0.294 d_{i j}\right)$ for fare and $9.82 \mathrm{~min}$ for headway.

The subsidy is zero and fares are at a higher level for both FF and DBF under the OP models in this numerical study, which means that the subsidy constraint is not binding. For comparison, it must be noted that the problem studied in Sun et al. [25] differs from the one presented here. Sun et al. [25] reported that the financial constraint is binding at optimality in public transit subsidization, and the operators break even after subsidies. However, the subsidy constraint is not binding at optimality when considering the OP models, i.e., $\widetilde{S}_{\text {flat }}=0$ (or $\widehat{S}_{\text {distance }}=0$ ). Thus, when the OP is positive, no subsidy is needed. In the case of high demand and fares, this is reasonable because operators seek to maximize their profits. The previous study considered the situation where the optimal profit was negative and proposed an efficiency-oriented subsidy optimization method that seeks to maximize the per capita subsidy, so there was an operating deficit in Case [12]12.

4.2. Fare Structures Discussion. The elastic demand function used in this paper is sensitive to the trip length. The travel behavior (i.e., demand and trip length) of passengers under FF and DBF is shown in Figure 1, which plots the demand and fares vs. trip length. When a passenger's trip length is $9.93 \mathrm{~km}, \mathrm{FF}$ and DBF fares are equal. When the trip is below $9.93 \mathrm{~km}$, the demand with DBF exceeds that with FF, but the fare with DBF is lower than with FF.

Taking the maximum demand gap for example, in the first set of the data (i.e., the first bars indicating demands under FF and DBF in Figure 1(a)), DBF demand is 1.5 times that under FF, whereas FF fare is 2.25 times that under DBF. Therefore, the FF revenue is higher than that under DBF (as shown in Table 1). In Figure 1(b), the DBF demand declines 
TABle 2: Notation.

\begin{tabular}{|c|c|c|}
\hline Parameters & Description & Baseline value \\
\hline$c_{O}$ & Average train operating cost per hour (¥/h-vehicle) & 1950 \\
\hline$e_{w}$ & Elasticity parameter for wait time $(1 / \mathrm{h})$ & 0.6 \\
\hline$e_{r}$ & Elasticity parameter for riding time $(1 / \mathrm{h})$ & 0.15 \\
\hline$e_{p}$ & Elasticity parameter for the fare $(1 / ¥)$ & 0.1 \\
\hline$L_{S}^{p}$ & Number of stations & 19 \\
\hline$P_{w}$ & Lower boundary of the fare (¥) & 0 \\
\hline$\frac{w}{P_{w}}$ & Upper boundary of the fare (¥) & 7 \\
\hline$t_{0}$ & Train dwell time at each station (h) & $1 / 120$ \\
\hline$t_{Z}$ & Train reversing time $(\mathrm{h})$ & 0.08 \\
\hline$v$ & Train speed $(\mathrm{km} / \mathrm{h})$ & 40 \\
\hline$\beta$ & Idle trains multiplier (the cost of the nonoperating trains is $\beta$-times of the operating trains) & 0.24 \\
\hline$\gamma_{0}$ & Fixed maintenance costs per line kilometer $(¥ / \mathrm{km})$ & 3800 \\
\hline$\gamma_{1}$ & Cost parameter related to the rail line frequency $(¥ / \mathrm{h})$ & 525 \\
\hline$\varepsilon$ & Reserve factor (the nonoperating trains are $\varepsilon$-times the number of the operating trains) & 0.25 \\
\hline$\sigma$ & Ratio of waiting time to headway $(1 / \mathrm{h})$ & 0.5 \\
\hline$\underline{\tau}$ & Lower boundary of the headway (h) & $1 / 30 \mathrm{~h}$ (or 2 minutes) \\
\hline$\overline{\bar{\tau}}$ & Upper boundary of the headway (h) & $1 / 5 \mathrm{~h}$ (or 12 minutes) \\
\hline$\Lambda_{0}$ & Fixed cost parameter for each station (¥/km) & 4200 \\
\hline$\Lambda_{1}$ & Service cost parameter per passenger at each station ( $¥)$ & 0.5 \\
\hline
\end{tabular}

TABLE 3: Optimized solution.

\begin{tabular}{lcc}
\hline Optimized solution & FF & DBF \\
\hline Fare $(¥)$ & 4.88 & $1.97+0.294 d_{i j}$ \\
Headway (min) & 8.56 & 9.82 \\
Revenue (¥/h) & 283754.21 & 245907.52 \\
Operating costs (¥/h) & 214949.64 & 218266.28 \\
Operator profit $(¥ / \mathrm{h})$ & 68804.57 & 27641.24 \\
Passenger surplus (¥/h) & 146131.37 & 225264.98 \\
Total social welfare (¥/h) & 214935.94 & 252906.22 \\
Subsidy (¥/h) & 0 & 0 \\
Demand (pass./h) & 57967 & 70989 \\
\hline
\end{tabular}

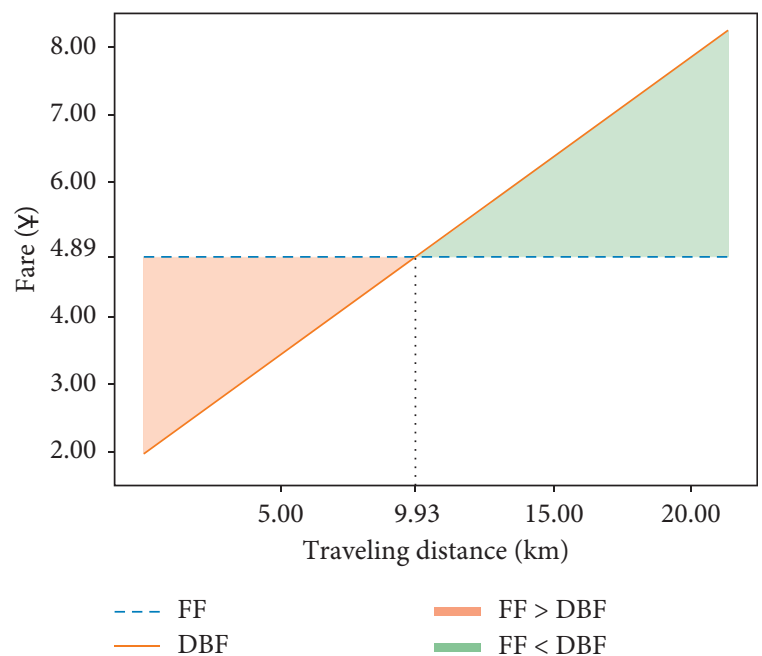

(a)

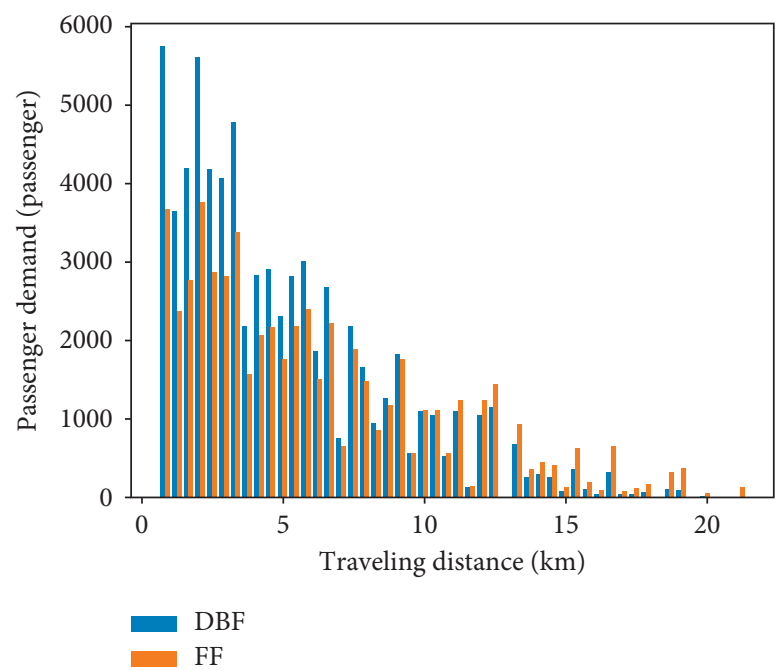

(b)

Figure 1: Demand and fare for a given operation plan. 


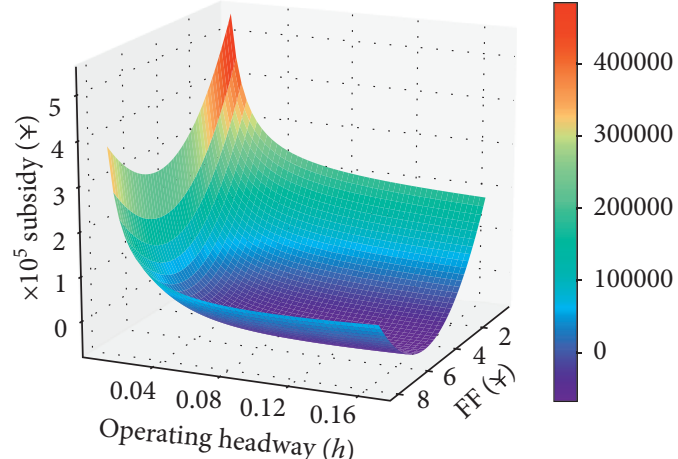

(a)

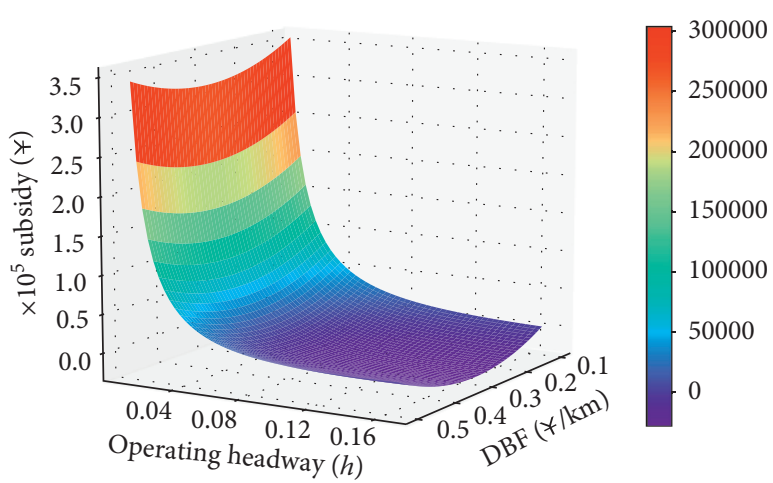

(b)

Figure 2: Decision variables vs. subsidy under FF and DBF. (a) FF. (b) DBF.

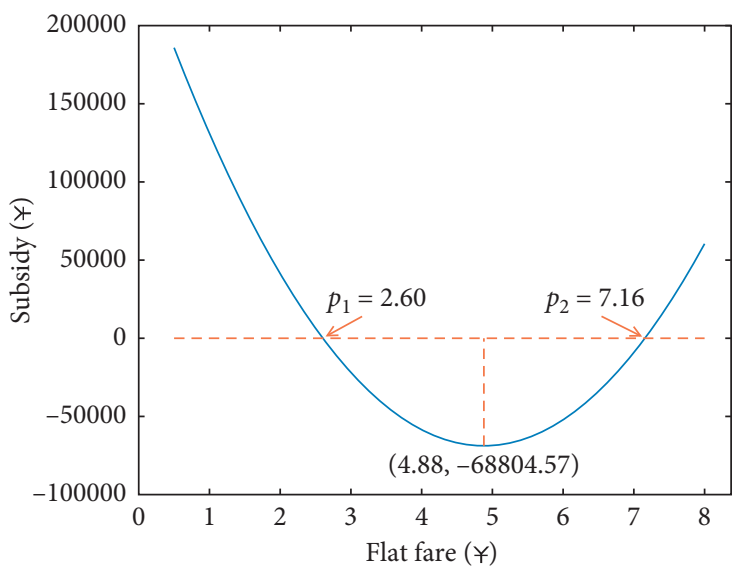

(a)

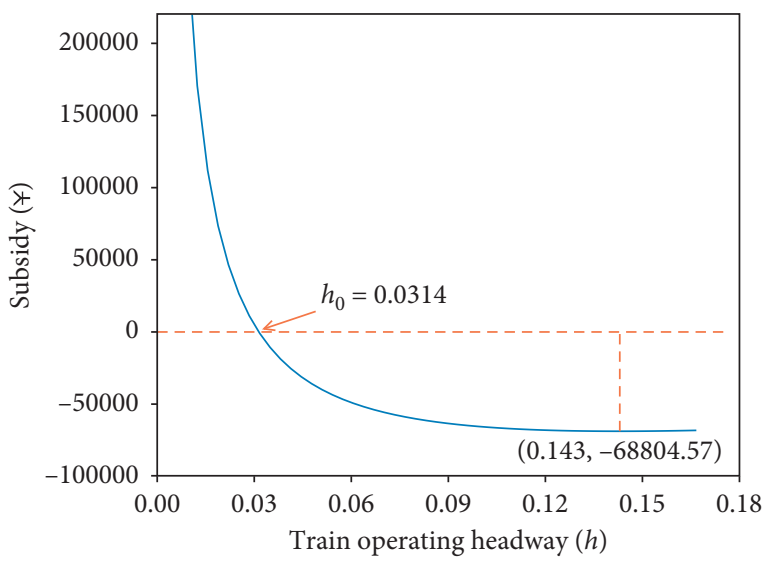

(b)

Figure 3: Subsidy vs. decision variables under FF.

when the trip exceeds $9.93 \mathrm{~km}$. The DBF demand is almost zero when the trip exceeds $17 \mathrm{~km}$, but there are still some passengers under FF. This occurs because the profit loss caused by the reduction in demand exceeds the profit gain caused by the increase in fares (i.e., the increase in the fare is not enough to compensate for the reduction in demand). For example, the DBF fare is about $¥ 5.88$ when the trip is $17 \mathrm{~km}$, which is 1.32 times higher than FF, but the demand is less than 0.5 of that under FF (in Figure 1).

\subsection{Subsidy Discussion and Operator Performance}

4.3.1. Effects of Subsidies on Operator Profit. Figures 2(a) and 2(b) show the changes in subsidies as the fares and headway change under FF and DBF. The trend under the two fare structures is similar, and the subsidy has a negative correlation with fare and headway, as expected. As can be seen, the subsidy under DBF decreases faster as the headway increases, compared to the change of the subsidy with the change of the fare. In contrast, the subsidy under FF changes more significantly as the fare changes. The blue part of Figure 2 shows the operator needs a lower subsidy, while the red part shows the operator needs a higher subsidy. In contrast, at the same headway, higher fares increase revenue. Note that the vertical scale in Figure 2 extends below zero, to allow for a possible negative profit.

Figures 3 and 4 show numerical results associated with various subsidies under FF and DBF. Considering the relation between subsidy and fare with fixed optimal headway $\widetilde{H}^{*}$ (see Figure 3(a)), as FF fare increases, the subsidy decreases from a peak value towards a minimum value, dropping to zero when $\widetilde{P}_{1}=2.60$. However, the subsidy reaches its vertex (minimum value of $¥-68804.57$ ) when the FF fare is $¥ 4.88$ (i.e., the operator needs no subsidies when the profit exceeds $¥ 0.0$ ). Beyond the value of FF fare at the vertex, the subsidy rises in a parabolic form from its minimum value, crossing the point of zero value where $\widetilde{P}_{2}=7.16$. For a fixed optimal fare $\widetilde{P}^{*}$ (see Figure $3(\mathrm{~b})$ ), the subsidy becomes zero when $\widetilde{H}=0.0314 \mathrm{~h}$. The graph shows 


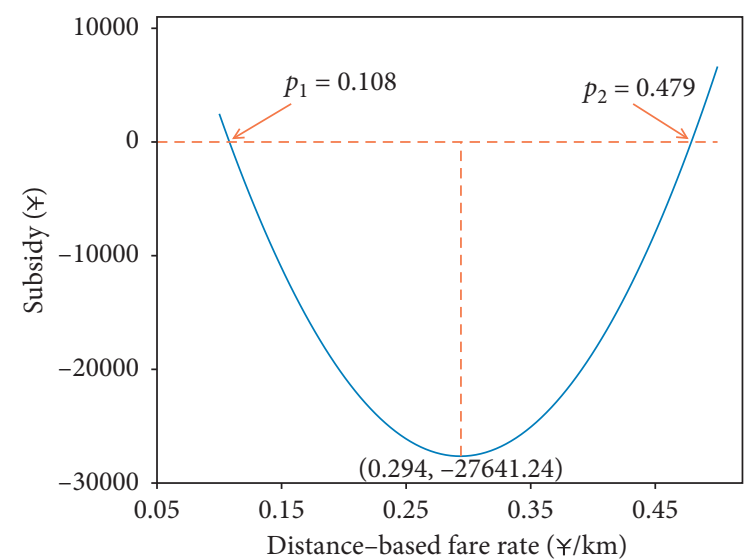

(a)

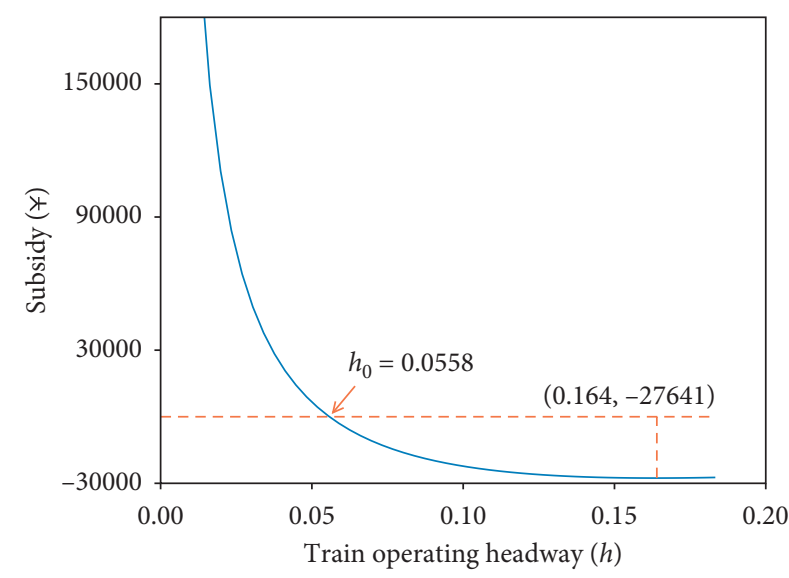

(b)

Figure 4: Subsidy vs. decision variables under DBF.

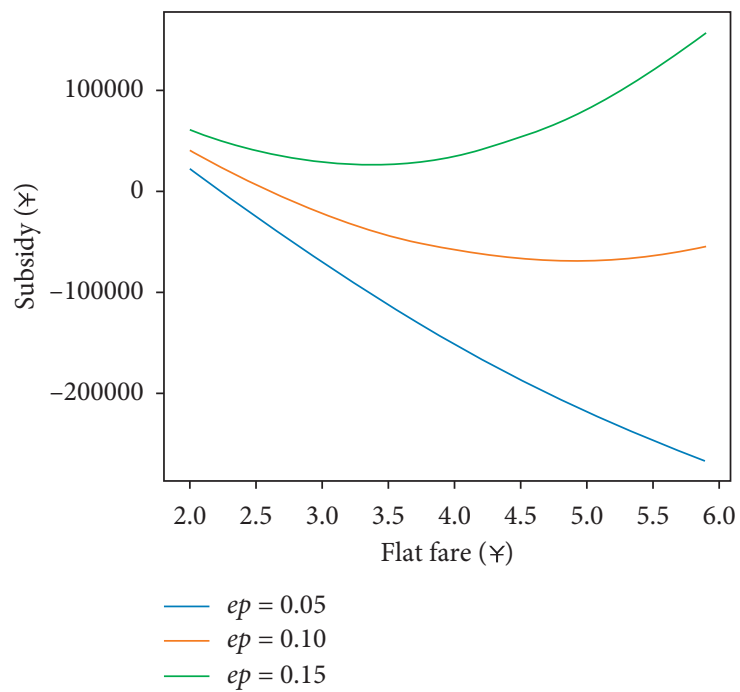

(a)

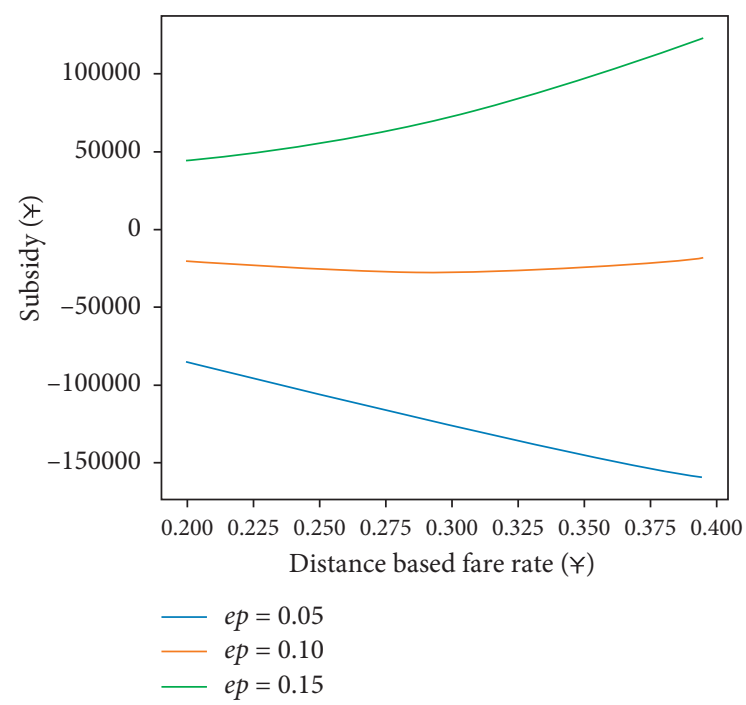

(c)

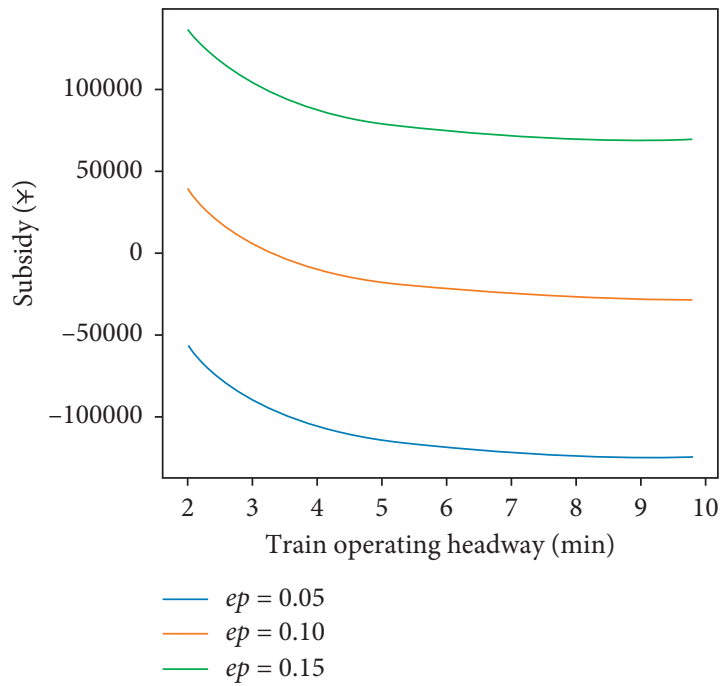

(b)

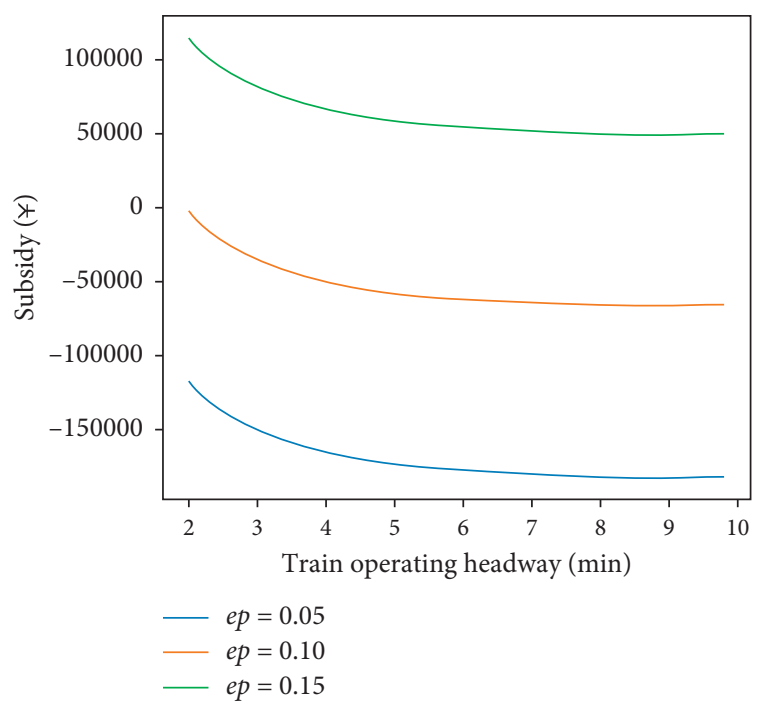

(d)

Figure 5: Subsidy vs. fare and headway under FF ((a) and (b)) and DBF ((c) and (d)) with three fare elasticity parameters. 
TABLE 4: Optimal solutions with different fare parameters.

\begin{tabular}{lcccccc}
\hline \multirow{2}{*}{ Optimal solution } & \multicolumn{2}{c}{$e_{p}=0.05$} & \multicolumn{2}{c}{$e_{p}=0.10$} & $e_{p}=0.15$ \\
& FF & DBF & FF & DBF & FF & 3.3 \\
\hline Fare (¥) & 9.64 & $1.97+0.78 d_{i j}$ & 4.88 & $1.97+0.29 d_{i j}$ & $1.97+0.13 d_{i j}$ \\
Headway (minute) & 5.93 & 7.07 & 8.56 & 9.82 & 10.71 & 1841.79 .53 \\
Revenue (¥/h) & 585051.39 & 447631.76 & 283754.21 & 245907.52 & 173515.54 \\
Operating cost (¥/h) & 227269.12 & 230116.67 & 214949.64 & 218266.28 & 208770.53 \\
Operator profit (¥/h) & 357782.27 & 217515.09 & 68804.57 & 27641.24 & -24658.00 & -311604.70 \\
Passenger surplus (¥/h) & 316619.46 & 549028.77 & 146131.37 & 225264.98 & 90194.69 & 123887.64 \\
Social welfare (¥/h) & 674401.73 & 766543.86 & 214935.94 & 252906.22 & 65536.69 & 85798.48 \\
Subsidy (¥/h) & 0 & 0 & 0 & 0 & 24658.00 & 38089.16 \\
Demand (Pas./h) & 60527 & 77814 & 57967 & 70989 & 55621 \\
\hline
\end{tabular}

the subsidy attains a minimum value of $¥-68804.57$ at a headway of 0.143 hours (8.56 minutes).

For DBF (see Figure 4), a similar trend is observed to that for FF. For a fixed optimized headway $\widehat{H}^{*}$ (see Figure 4(a)), the optimized subsidy is $¥-27641.24$ when the fare is $¥$ $\left(1.97+0.294 d_{i j}\right)$. When $\widehat{P}^{*}=E 1.97+0.108 d_{i j}$ and $\widehat{P}^{*}=E$ $1.97+0.479 d_{i j}$, the subsidy is zero. The reason is similar to that for FF. For a fixed optimized fare $\widehat{P}^{*}$ (see Figure 4(a)), when the subsidy is minimal, the headway is 0.164 hours (9.82 minutes). When $\widetilde{H}=0.0558 \mathrm{~h}$, the subsidy is zero.

\subsubsection{Effects of Fare Parameter on Operator Performance.} The fare levels significantly affect operator performance [7], thus affecting subsidies. Therefore, we explore the effects of fare elasticity parameter on subsidy. Figures 5(a)-5(d) compare the subsidies with the change of fare and headway for three elasticity factors: $e_{p}=0.05, e_{p}=0.10$, and $e_{p}=0.15$.

Note that Figures 5(a) and 5(b) represent the changes of subsidy for different fare and headway under FF, while Figures 5(c) and 5(d) represent the changes under DBF. The effects of the fare and headway on the subsidy under FF and DBF show similar trends, but the fare and headway trends are somewhat different. It is found that a larger $e_{p}$-value requires higher subsidies. A smaller $e_{p}$-value indicates higher demand and fares, and hence a more profitable operation.

Table 4 further presents the optimized URT system solutions for three elasticity factors: $e_{p}=0.05, e_{p}=0.10$, and $e_{p}=0.15$. Comparing the effects of changes in fare elasticity factor on operator performance, passenger behavior, and subsidies under FF and DBF, the fare elasticity factor has a more significant effect on fares and demand, and thus the subsidy varies more widely. For FF, the comparison shows that the FF fare decreases by $65.8 \%$; i.e., the FF fare decreases from $¥ 9.64$ to $¥ 3.3$ for fare elasticity factors of $e_{p}=0.05$ and $e_{p}=0.15$, respectively. For DBF, the fare elasticity factor has a more significant effect on the variable component of DBF fare which decreases by $83.3 \%$, i.e., the variable component of DBF fare decreases from $¥ 0.78 / d_{i j}$ to $¥ 0.13 / d_{i j}$ for fare elasticity factors of $e_{p}$ of 0.05 and 0.15 , respectively.

When $e_{p}$ remains at the same level, it has a similar effect on the subsidies under the two fare structures. As $e_{p}$ increases, the social welfare gradually decreases and a deficit occurs at the lower fare and demand. Therefore, the subsidies rise from zero to $¥ 24658.00$ and $¥ 38089.16$ under the FF and DBF. In addition, the revenues of two fare structures differ greatly (reduced by $68.53 \%$ and $61.24 \%$ ), whereas the operating cost of FF and DBF decrease by only $8.14 \%$ and $8.04 \%$. The reason is that $e_{p}$ significantly affects fares and demand, which have a greater effect on revenue than on operating cost. It is found that the subsidy is zero when $e_{p}$ is 0.05 or 0.10 because if the fare and demand are high, the revenue exceeds the operating cost. The same is true for DBF.

\section{Conclusions}

This study focuses mainly on service design and subsidy issues and investigates subsidies to URT operators. The operator profit (OP) model primarily considers demand and train operation plan to pursue operating profit. This study extends the existing literature on operator performance and passenger characteristics under subsidy constraints by considering fare structures. The numerical examples explore the operator performance and passenger characteristics by comparing different fare structures. Operator performance is mainly measured by service level (e.g., service frequency) and operational subsidies needed from the government, while the comparative analysis under FF and DBF reflects the passengers' behavior. By analyzing the OP model, this paper provides some important findings.

(1) This paper analyzes the operator's profit with fare structures and subsidy constraints while comparing the impact and performance of FF and DBF through proposed models and numerical results. Assuming that the passengers' travel behavior is homogenous, the results for different fare structures are slightly different (as in Table 2). The influence of decision variables on the operational subsidies under FF exceeds that under DBF (shown in Figures 3 and 4). In general, $\mathrm{DBF}$ is more attractive for short-distance passengers, while FF is more attractive for longdistance passengers (see Figure 1).

(2) The subsidy is zero under the OP models in this numerical study, which means that the subsidy constraint is not binding. Profit maximization does 
not require subsidies. If profit is negative when the social welfare is positive, then a subsidy may raise the profit to zero ("break-even") but should not raise it further. Wang and Deng [12] considered the situation where the optimal profit was negative and proposed an efficiency-oriented subsidy optimization method that seeks to maximize the per capita subsidy, so there is an operating deficit in that case.

(3) The fare structures and levels significantly affect operator performance, thus affecting subsidies to operators. Comparing the effects of changes in the fare elasticity factor on subsidies under FF and DBF, we find that a larger fare parameter value requires higher subsidies. A smaller fare parameter value indicates higher demand, so the operation is more profitable (see Figure 5 and Table 4).

Although the proposed model provides useful insights into operation and policy evaluation of URT, it neglects some important URT characteristics that should be considered in the future. In further studies, work should be pursued in the following areas.

(1) In this paper, the subsidy is computed based on the headways and fares, which means the subsidy is treated as a financial constraint. From the perspective of management, it represents a cost-plus contract widely applied in China, in which operating losses are fully covered by the government. Future studies may consider additional policies and incentive mechanisms to induce operators to reduce operating costs and improve services.
(2) The models presented here focus on the operator profit with subsidy constraints but ignore the effects of passenger choices and behaviors on subsidies. The current study may be extended to consider the effects of service levels and passenger travel choices on subsidies.

(3) A linear form of elastic demand function is used in this paper, which depends on the travel times and fares (FF and DBF). The fares are the same for all passengers under FF while they vary with the trip length under DBF. In the future, fares that vary over time or for different passenger types (e.g., students, the elderly, and the disabled) may be considered.

\section{Appendix}

\section{A. Proof Progress}

To obtain the optimal solutions for the headway and fare, we set the partial derivative of the objective function $\tilde{\pi}(\widetilde{H}, \widetilde{P})$ (or $\widehat{\pi}(\widehat{H}, \widehat{P})$ ) with respect to $\widetilde{H}$ (or $\widehat{H}$ ) and $\widetilde{P}$ (or $\widehat{P}$ ) to zero. For FF,

$$
\left\{\begin{array}{l}
\frac{\partial \widetilde{\pi}(\widetilde{H}, \widetilde{P})}{\partial \widetilde{P}}=\sum_{i, j \in S} q_{i j}\left(1-e_{w} \sigma \widetilde{H}-e_{r} r_{t}-2 e_{p} \widetilde{P}+e_{p} \Lambda_{1}\right)=0 \\
\frac{\partial \widetilde{\pi}(\widetilde{H}, \widetilde{P})}{\partial \widetilde{H}}=e_{w} \sigma \sum_{i, j \in S} q_{i j}\left(\Lambda_{1}-\widetilde{P}\right)+\frac{(1+\beta \varepsilon) T_{R} \cdot c_{O}+\gamma_{1}}{\widetilde{H}^{2}}=0
\end{array}\right.
$$

For DBF, we have

$$
\left\{\begin{array}{l}
\frac{\partial \widehat{\pi}(\widehat{H}, \widehat{P})}{\partial \widehat{P}}=\sum_{i, j \in S} d_{i j} q_{i j}\left(1-e_{w} \sigma \widehat{H}-e_{r} r_{t}-2 e_{p}\left(p_{0}+\widehat{p} d_{i j}\right)+e_{p} \Lambda_{1}\right)=0 \\
\frac{\partial \widehat{\pi}(\widehat{H}, \widehat{P})}{\partial \widehat{H}}=e_{w} \sigma \sum_{i, j \in S} q_{i j}\left(\Lambda_{1}-\left(p_{0}+\widehat{p} d_{i j}\right)\right)+\frac{(1+\beta \varepsilon) T_{R} \cdot c_{O}+\gamma_{1}}{\widehat{H}^{2}}=0 .
\end{array}\right.
$$

Then, we obtain the optimality conditions.

For FF,

$$
\left\{\begin{array}{l}
\widetilde{P}^{*}=\frac{\sum_{i, j \in S} q_{i j}\left(1-e_{w} \sigma \tilde{H}-e_{r} r_{t}+\Lambda_{1} e_{p}\right)}{2 e_{p} \sum_{i, j \in S} q_{i j}}, \\
\widetilde{H}^{*}=\sqrt{\frac{(1+\beta \varepsilon) T_{R} \cdot c_{O}+\gamma_{1}}{e_{w} \sigma\left(\widetilde{P}-\Lambda_{1}\right) \sum_{i, j \in S} q_{i j}}}
\end{array}\right.
$$

For DBF,

$$
\left\{\begin{array}{l}
\widehat{P}^{*}=\frac{\sum_{i, j \in S} d_{i j} q_{i j}\left(1-e_{w} \sigma \widehat{H}-e_{r} r_{t}+e_{p} \Lambda_{1}\right)}{2 e_{p} \sum_{i, j \in S} q_{i j} \mathrm{~d}_{i j}}, \\
\widehat{H}^{*}=\sqrt{\frac{(1+\beta \varepsilon) T_{R} \cdot c_{O}+\gamma_{1}}{e_{w} \sigma \sum_{i, j \in S} q_{i j}\left(\left(p_{0}+\widehat{p} d_{i j}\right)-\Lambda_{1}\right)}} .
\end{array}\right.
$$

Substituting (A.3) and (A.4) into objective functions (12) or (13), and considering the constraint $\widetilde{S}_{\text {flat }}=\max \{\widetilde{C}-\widetilde{R}, 0\}$ or $\widehat{S}_{\text {distance }}=\max \{\widehat{C}-\widehat{R}, 0\}$, we obtain the subsidy to an operator under FF and DBF as follows. 
For FF,

$$
\widetilde{S}_{\text {flat }}^{*}=\max \left\{(1+\beta \varepsilon) \frac{c_{O} T_{R}}{\widetilde{H}^{*}}+\left(\gamma_{0} D_{s}+\frac{\gamma_{1}}{\widetilde{H}^{*}}\right)+\Lambda_{0} L_{S}+\left(\Lambda_{1}-\widetilde{P}^{*}\right) \sum_{i, j \in S} q_{i j}\left(1-e_{w} \sigma \widetilde{H}^{*}-e_{r} r_{t}-e_{p} \widetilde{P}^{*}\right), 0\right\} .
$$

For DBF,

$$
\widehat{S}_{\text {distance }}^{*}=\max \left\{(1+\beta \varepsilon) \frac{c_{O} T_{R}}{\widehat{H}^{*}}+\left(\gamma_{0} D_{s}+\frac{\gamma_{1}}{\widehat{H}^{*}}\right)+\Lambda_{0} L_{S}+\sum_{i, j \in S}\left(\Lambda_{1}-\widehat{P}^{*}\right) q_{i j}\left(1-e_{w} \sigma \widehat{H}^{*}-e_{r} r_{t}-e_{p}\left(p_{0}+\widehat{p} d_{i j}\right)\right), 0\right\} \text {. }
$$

The second-order partial derivatives of $\tilde{\pi}(\widetilde{H}, \widetilde{P})$ (or $\widehat{\pi}(\widehat{H}, \widehat{P})$ ) and with respect to $\widetilde{H}$ (or $\widehat{H}$ ) and $\widetilde{P}$ (or $\widehat{P}$ ) can be derived as follows. For FF,

$$
\left\{\begin{array}{l}
\frac{\partial^{2} \widetilde{\pi}(\widetilde{H}, \widetilde{P})}{\partial \widetilde{P}^{2}}=-2 e_{p} \sum_{i, j \in S} q_{i j}, \\
\frac{\partial^{2} \widetilde{\pi}(\widetilde{H}, \widetilde{P})}{\partial \widetilde{H}^{2}}=-2 \frac{(1+\beta \varepsilon) T_{R} \cdot c_{O}+\gamma_{1}}{\widetilde{H}^{3}}, \\
\frac{\partial^{2} \widetilde{\pi}(\widetilde{H}, \widetilde{P})}{\partial \widetilde{P} \partial \widetilde{H}}=\frac{\partial^{2} \widetilde{\pi}(\widetilde{H}, \widetilde{P})}{\partial \widetilde{H} \partial \widetilde{P}}=-e_{w} \sigma \sum_{i, j \in S} q_{i j} .
\end{array}\right.
$$

For DBF,

$$
\left\{\begin{array}{l}
\frac{\partial^{2} \widehat{\pi}(\widehat{H}, \widehat{P})}{\partial \widehat{P}^{2}}=-2 e_{p} \sum_{i, j \in S} q_{i j} d_{i j}^{2}, \\
\frac{\partial^{2} \widehat{\pi}(\widehat{H}, \widehat{P})}{\partial \widehat{H}^{2}}=-2 \frac{(1+\beta \varepsilon) T_{R} \cdot c_{O}+\gamma_{1}}{\widehat{H}^{3}}, \\
\frac{\partial^{2} \widehat{\pi}(\widehat{H}, \widehat{P})}{\partial \widehat{P} \partial \hat{H}}=\frac{\partial^{2} \widehat{\pi}(\widehat{H}, \widehat{P})}{\partial \widehat{H} \partial \widehat{P}}=-e_{w} \sigma \sum_{i, j \in S} q_{i j} \mathrm{~d}_{i j} .
\end{array}\right.
$$

According to (A.7) and (A.8), we can obtain the following Hessian matrices under FF and DBF, respectively. For FF,

$$
\begin{aligned}
& \operatorname{Hessian}(\widetilde{\pi})=\left[\begin{array}{ll}
\frac{\partial^{2} \widetilde{\pi}(\widetilde{H}, \widetilde{P})}{\partial \widetilde{H}^{2}} & \frac{\partial^{2} \widetilde{\pi}(\widetilde{H}, \widetilde{P})}{\partial \widetilde{H} \partial \widetilde{P}} \\
\frac{\partial^{2} \widetilde{\pi}(\widetilde{H}, \widetilde{P})}{\partial \widetilde{P} \partial \widetilde{H}} & \frac{\partial^{2} \widetilde{\pi}(\widetilde{H}, \widetilde{P})}{\partial \widetilde{P}^{2}}
\end{array}\right] \\
& =\left[\begin{array}{cc}
-2 \frac{(1+\beta \varepsilon) T_{R} \cdot c_{O}+\gamma_{1}}{\widehat{H}^{3}} & -e_{w} \sigma \sum_{i, j \in S} q_{i j} \\
-e_{w} \sigma \sum_{i, j \in S} q_{i j} & -2 e_{p} \sum_{i, j \in S} q_{i j}
\end{array}\right] \\
& =4 \frac{(1+\beta \varepsilon) T_{R} \cdot c_{O}+\gamma_{1}}{\widetilde{H}^{3}} e_{p} \sum_{i, j \in S} q_{i j}-\left(e_{w} \sigma \sum_{i, j \in S} q_{i j}\right)^{2} .
\end{aligned}
$$

For DBF, 


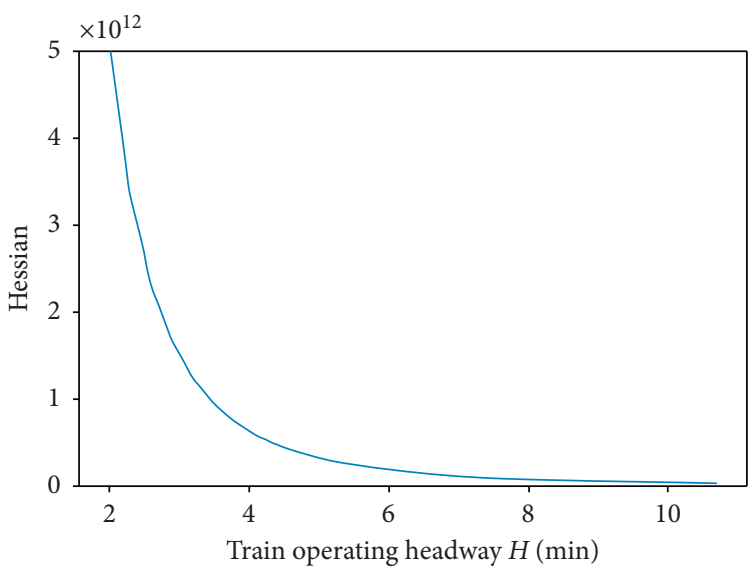

(a)

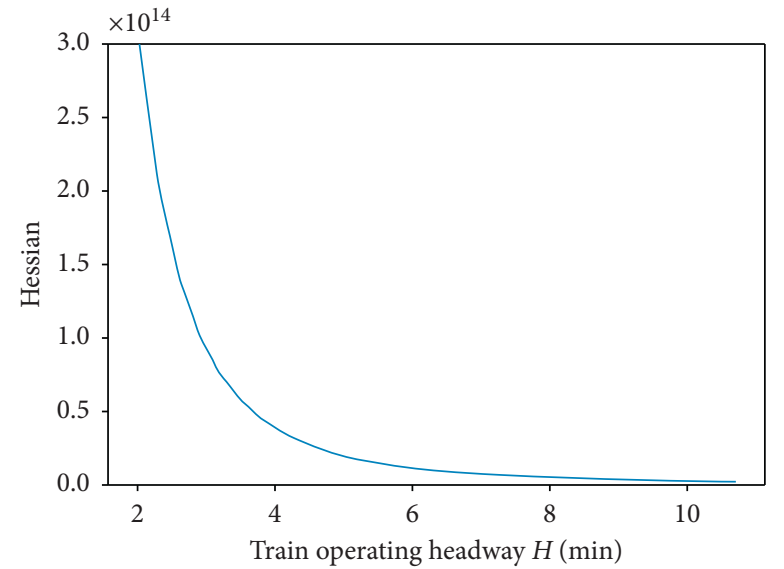

(b)

Figure 6: The value of Hessian matrices under the two different fare structures. (a) FF. (b) DBF.

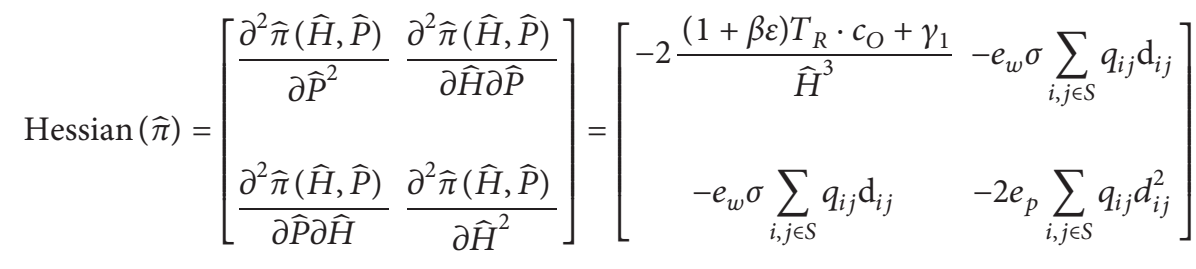

$$
\begin{aligned}
& =4 \frac{(1+\beta \varepsilon) T_{R} \cdot c_{O}+\gamma_{1}}{\widehat{H}^{3}} e_{p} \sum_{i, j \in S} q_{i j} d_{i j}^{2}-\left(e_{w} \sigma \sum_{i, j \in S} q_{i j} \mathrm{~d}_{i j}\right)^{2} \text {. }
\end{aligned}
$$

As shown in Figure 6, all values of the Hessian matrices $\tilde{\pi}$ and $\hat{\pi}$ are greater than zero, that is, Hessian $(\tilde{\pi})>0$ and Hessian $(\hat{\pi})>0$. We can find that the Hessian matrices are negative definite through specific numerical analysis, but the sign of the Hessian matrices cannot be determined in the analytical solution. This implies that there is at least one feasible solution for operator profit (OP) models, and we can derive optimality conditions about the fare, headway, and subsidy from (A.3)-(A.6).

\section{Data Availability}

The data used to support the findings of this study are available from the corresponding author upon request.

\section{Conflicts of Interest}

The authors declare that they have no conflicts of interest.

\section{Acknowledgments}

This research was supported by the National Natural Science Foundation Council of China (nos. 71871226 and 71471179); the Graduate education reform project of Hunan Province (no. 150110005); and the China Scholarship Council (no. 201906370095).

\section{References}

[1] China Association of Metros, Data Source: Annual Statistics and Analysis Report of URT 2019, China Association of Metros, Beijing, China, 2019.

[2] R. Z. Farahani, E. Miandoabchi, W. Y. Szeto, and H. Rashidi, "A review of urban transportation network design problems," European Journal of Operational Research, vol. 229, no. 2, pp. 281-302, 2013.

[3] X. Li and P. E. D. Love, "Employing land value capture in urban rail transit public private partnerships: retrospective analysis of Delhi's airport metro express," Research in Transportation Business \& Management, vol. 32, Article ID 100431, 2019.

[4] D. Canca, A. De-Los-Santos, G. Laporte, and J. A. Mesa, "Integrated railway rapid transit network design and line planning problem with maximum profit," Transportation Research Part E: Logistics and Transportation Review, vol. 127, pp. 1-30, 2019.

[5] Y. Tang, Y. Jiang, H. Yang, and O. A. Nielsen, "Modeling and optimizing a fare incentive strategy to manage queuing and crowding in mass transit systems," Transportation Research Part B: Methodological, vol. 138, pp. 247-267, 2020.

[6] I. K. Pitcher and S. G. Tesche, A Review of Fare Structures for Melbourne, Australia, Paper presented at the 82nd TRB Annual Meeting, Washington, DC, USA, 2003.

[7] W. H. K. Lam and J. Zhou, "Optimal fare structure for transit networks with elastic demand," Transportation Research 
Record: Journal of the Transportation Research Board, vol. 1733, no. 1, pp. 8-14, 2000.

[8] S. I.-J. Chien and L. N. Spasovic, "Optimization of grid bus transit systems with elastic demand," Journal of Advanced Transportation, vol. 36, no. 1, pp. 63-91, 2002.

[9] N. Sharaby and Y. Shiftan, "The impact of fare integration on travel behavior and transit ridership," Transport Policy, vol. 21, no. 4, pp. 63-70, 2012.

[10] S. I.-J. Y. Chien and C. F. M. Tsai, "Optimization of fare structure and service frequency for maximum profitability of transit systems," Transportation Planning and Technology, vol. 30, no. 5, pp. 477-500, 2007.

[11] Z. Jin, J.-D. Schmöcker, and S. Maadi, "On the interaction between public transport demand, service quality and fare for social welfare optimisation," Research in Transportation Economics, vol. 76, Article ID 100732, 2019.

[12] Q. Wang and L. Deng, "Integrated optimization method of operational subsidy with fare for urban rail transit," Computers \& Industrial Engineering, vol. 127, no. 127, pp. 1153$1163,2019$.

[13] Y. Yang, L. B. Deng, Q. Wang, and W. L. Zhou, "Zone fare system design in a rail transit line," Journal of Advanced Transportation, vol. 2020, Article ID 2470579, 10 pages, 2020.

[14] W. W. Wang, D. Z. W. Wang, H. Sun, and J. Wu, "Public transit service operation strategy under indifference thresholds-based bi-modal equilibrium," Journal of Advanced Transportation, vol. 50, no. 6, pp. 1124-1138, 2016.

[15] F. M. Tsai, S. Chien, and C. H. Wei, "Joint optimization of temporal headway and differential fare for transit systems considering heterogeneous demand elasticity," Journal of Transportation Engineering, vol. 139, no. 1, pp. 30-39, 2012.

[16] S. Sun and W. Y. Szeto, "Optimal sectional fare and frequency settings for transit networks with elastic demand," Transportation Research Part B: Methodological, vol. 127, pp. 147$177,2019$.

[17] D. Huang, Z. Liu, P. Liu, and J. Chen, "Optimal transit fare and service frequency of a nonlinear origin-destination based fare structure," Transportation Research Part E: Logistics and Transportation Review, vol. 96, pp. 1-19, 2016.

[18] C. Nuworsoo, A. Golub, and E. Deakin, "Analyzing equity impacts of transit fare changes: case study of Alameda-Contra Costa Transit, California," Evaluation and Program Planning, vol. 32, no. 4, pp. 360-368, 2009.

[19] S. R. Jara-Díaz and A. Gschwender, "The effect of financial constraints on the optimal design of public transport services," Transportation, vol. 36, no. 1, pp. 65-75, 2009.

[20] L. J. Basso and H. E. Silva, "Efficiency and substitutability of transit subsidies and other urban transport policies," American Economic Journal: Economic Policy, vol. 6, no. 4, pp. 1-33, 2014.

[21] K. Gkritza, M. G. Karlaftis, and F. L. Mannering, "Estimating multimodal transit ridership with a varying fare structure," Transportation Research Part A: Policy and Practice, vol. 45, no. 2, pp. 148-160, 2011.

[22] C. D. Nassi and F. C. d. C. d. Costa, "Use of the analytic hierarchy process to evaluate transit fare system," Research in Transportation Economics, vol. 36, no. 1, pp. 50-62, 2012.

[23] Y. Zhou, H. S. Kim, P. Schonfeld, and E. Kim, "Subsidies and welfare maximization tradeoffs in bus transit systems," The Annals of Regional Science, vol. 42, no. 3, pp. 643-660, 2008.

[24] Q. Wang, L. B. Deng, and G. M. Xu, "Operational subsidy optimization in urban rail transit under the break-even mode: considering two fare regimes," Computers \& Industrial Engineering, vol. 149, 2020.
[25] Y. Sun, Q. Guo, P. Schonfeld, and Z. Li, "Implications of the cost of public funds in public transit subsidization and regulation," Transportation Research Part A: Policy and Practice, vol. 91, pp. 236-250, 2016.

[26] S. Ling, N. Jia, S. Ma, Y. Lan, and W. Hu, "An incentive mechanism design for bus subsidy based on the route service level," Transportation Research Part A: Policy and Practice, vol. 119, pp. 271-283, 2019.

[27] Y. Sun and P. M. Schonfeld, "Optimization models for public transit operations under subsidization and regulation," Transportation Research Record: Journal of the Transportation Research Board, vol. 2530, no. 1, pp. 44-54, 2015a.

[28] G. Kocur and C. Hendrickson, "Design of local bus service with demand equilibration," Transportation Science, vol. 16, no. 2, pp. 113-260, 1982.

[29] China Railway Fourth Survey and Design Institute Group Co., Ltd, Feasibility Study Report on the First Phase Project of Changsha Rail Line 2 [R], China Railway Fourth Survey and design Institute Group Co., Ltd., Wuhan, China, 2009. 